\title{
Intramyocellular lipid droplets and insulin sensitivity, the human perspective
}

Citation for published version (APA):

Gemmink, A., Goodpaster, B. H., Schrauwen, P., \& Hesselink, M. K. C. (2017). Intramyocellular lipid droplets and insulin sensitivity, the human perspective. Biochimica et Biophysica Acta-Molecular and Cell Biology of Lipids, 1862(10), 1242-1249. https://doi.org/10.1016/j.bbalip.2017.07.010

Document status and date:

Published: 01/10/2017

DOI:

10.1016/j.bbalip.2017.07.010

Document Version:

Publisher's PDF, also known as Version of record

Document license:

Taverne

Please check the document version of this publication:

- A submitted manuscript is the version of the article upon submission and before peer-review. There can be important differences between the submitted version and the official published version of record.

People interested in the research are advised to contact the author for the final version of the publication, or visit the DOI to the publisher's website.

- The final author version and the galley proof are versions of the publication after peer review.

- The final published version features the final layout of the paper including the volume, issue and page numbers.

Link to publication

\footnotetext{
General rights rights.

- You may freely distribute the URL identifying the publication in the public portal. please follow below link for the End User Agreement:

www.umlib.nl/taverne-license

Take down policy

If you believe that this document breaches copyright please contact us at:

repository@maastrichtuniversity.nl

providing details and we will investigate your claim.
}

Copyright and moral rights for the publications made accessible in the public portal are retained by the authors and/or other copyright owners and it is a condition of accessing publications that users recognise and abide by the legal requirements associated with these

- Users may download and print one copy of any publication from the public portal for the purpose of private study or research.

- You may not further distribute the material or use it for any profit-making activity or commercial gain

If the publication is distributed under the terms of Article $25 \mathrm{fa}$ of the Dutch Copyright Act, indicated by the "Taverne" license above, 
Review

\title{
Intramyocellular lipid droplets and insulin sensitivity, the human perspective $^{\text {tr }}$
}

\author{
Anne Gemmink ${ }^{\mathrm{a}}$, Bret H. Goodpaster ${ }^{\mathrm{b}}$, Patrick Schrauwen ${ }^{\mathrm{a}}$, Matthijs K.C. Hesselink ${ }^{\mathrm{a}, *}$ \\ a Department of Human Biology and Human Movement Sciences, NUTRIM School for Nutrition and Translational Research in Metabolism, Maastricht University Medical \\ Centre +, 6200MD Maastricht, The Netherlands \\ b Translational Research Institute for Metabolism and Diabetes, Orlando, FL, USA
}

\section{A R T I C L E I N F O}

\section{Keywords:}

Skeletal muscle

Insulin resistance

PLIN5

Human

IMCL

\begin{abstract}
A B S T R A C T
Skeletal muscle can store excess fat as subcellular lipid droplets (LDs). While originally viewed as uninteresting static balls of triacylglycerol, it is now clear that myocellular LDs play an active role in myocellular (patho) physiology. In this review we aim to discuss the role of LDs in muscle cell insulin sensitivity and identify parameters which appear to affect this relationship. Moreover, we discuss the application of novel tools permitting detailed examination of these parameters. This article is part of a Special Issue entitled: Recent Advances in Lipid Droplet Biology edited by Rosalind Coleman and Matthijs Hesselink.
\end{abstract}

\section{Introduction}

The ability of insulin to promote myocellular glucose uptake (insulin sensitivity) is a key feature of healthy skeletal muscle. Compromised insulin sensitivity is a hallmark for type 2 diabetes pathogenesis; hence, it is essential to understand the mechanisms that may impede insulin action. Impaired insulin signaling, with resultant insulin resistance, is a common observation in obesity. It has been widely hypothesized that obesity predisposes to insulin resistance, in large part because the capacity of white adipose tissue to store excess calories as fat is limited, and the excess fat is then stored in small lipid droplets (LDs) within non-adipose tissue such as the heart, the liver and skeletal muscle [1]. Especially under conditions when fat oxidative capacity is limited, increased inflow of fatty acids in skeletal muscle augments intramyocellular lipid (IMCL) content. Although it goes without saying that spill-over of fatty acids from adipose tissue contributes to myocellular fat content in the pathological state of obesity, IMCL is more than merely static lipid, and elevated IMCL levels can also be observed in the non-obese state and in the absence of spill-over of fatty acids from adipose tissue.

In insulin resistant individuals, IMCL scales negatively with insulin sensitivity. However, in insulin sensitive trained individuals this is not the case. To better understand the putative role of IMCL in insulin sensitivity, more insight into the processes involved in myocellular fat storage and degradation is warranted.
Myocellular fat is stored in relatively small sized LDs $\left(0.20-0.50 \mu \mathrm{m}^{2}\right)$, typically comprised of a neutral lipid core, in which fatty acids are being stored predominantly as triacylglycerol (TAG). This core is surrounded by a phospholipid monolayer coated by a variety of proteins involved in the storage and release of fatty acids in and from the droplet [2] (a process referred to as lipid droplet dynamics [3]).

Circumstantial evidence suggests that LD pools that are highly dynamic and possess a high turnover rate are less harmful to insulin sensitivity than static LD pools. The potential mechanisms underlying this observation, and the relationship between muscle LD and insulin sensitivity remains to be elucidated.

In this review we aim to provide a state-of-the art overview of the currently prevailing mechanisms linking lipid storage within the muscle cell to human muscle insulin sensitivity. Nowadays, imaging techniques to study LD dynamics are quickly developing. Hence, we also review experimental means and methods that will likely unveil subcellular mechanisms affecting the relationship between IMCL and insulin sensitivity as well as the role of LD in other aspects of health and disease.

\section{The intricate relationship between IMCL and insulin sensitivity}

Advances in ${ }^{1} \mathrm{H}$ NMR spectroscopy in the late nineties permitted non-invasive measurements of IMCL [4]. Taking advantage of this approach, multiple groups have shown a negative relationship between

\footnotetext{
This article is part of a Special Issue entitled: Recent Advances in Lipid Droplet Biology edited by Rosalind Coleman and Matthijs Hesselink.

* Corresponding author at: Department of Human Movement Sciences, NUTRIM School for Nutrition and Translational Research in Metabolism, Maastricht University Medical Centre +, 6200 MD Maastricht, The Netherlands.

E-mail address: matthijs.hesselink@maastrichtuniversity.nl (M.K.C. Hesselink).
} 


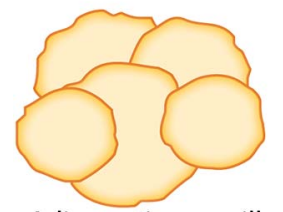

Adipose tissue spill over

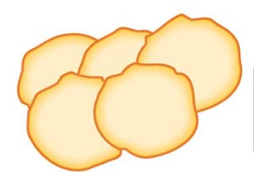

Fasting/post-exercise

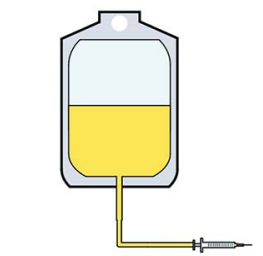

Lipid infusion



Fig. 1. Schematic depiction of various models contributing to elevated circulatory nonesterified (free) fatty acids and deposition of intramyocellular lipid (IMCL). Adipose tissue-derived fatty acids may increase due to limited adipose tissue expandability in the obese state (upper left example), free fatty acids may increase in the prolonged fasted state and augment IMCL (middle left example) and fatty acids can be experimentally elevated by infusing a lipid emulsion along with stimulation or modulation of lipoprotein lipase activity so that fatty acids are released from TAG particles to augment IMCL storage (lower left example).

IMCL content and insulin insensitivity [5,6] (for review see [7]). Augmenting IMCL content acutely using intravenous lipid infusions ameliorates myocellular insulin sensitivity [8], suggesting a causal relationship between IMCL and insulin resistance. Other models suggesting this relationship are myocellular over-expression of lipoprotein lipase which promotes liberation of fatty acids from circulatory TAG particles and profoundly augments IMCL content [9], and elevating plasma non-esterified fatty acid levels in a physiological way like prolonged fasting results in increased IMCL storage and insulin resistance [10] (Fig. 1).

Paradoxically, also trained athletes - who stand out for having very high insulin sensitivity - possess IMCL levels in the same range as obese insulin resistant or type 2 diabetic subjects, a phenomenon classically referred to as the 'athletes paradox' [11]. To explain this paradox, it has been suggested that the co-existence of compromised mitochondrial fat oxidation and high IMCL levels might be necessary to impede insulin sensitivity and that it is not the TAG in IMCL per se that is the wrongdoer, but that incomplete hydrolysis of TAG with elevated diacylglycerol (DAG) is the primary defect linking IMCL to insulin resistance [12] (for detailed discussion see below). Other factors, like LD coating, morphology and subcellular location have been suggested as well to explain the athlete's paradox. To put the current observations and the intricate relationship between IMCL and insulin sensitivity into perspective, the following sections will focus on how LD dynamics affects features of LDs supposedly involved in modulating the relationship between IMCL and insulin sensitivity (Fig. 2).

\subsection{Coating of lipid droplets with perilipins}

As outlined above, myocellular LDs are no longer regarded as static storage sites of fatty-acids spilled-over from adipose tissue. Instead, it has been shown that LDs have a highly dynamic nature that is tightly orchestrated by proteins involved in TAG turnover in the LDs. In skeletal muscle, the most important players are the two lipases, hormone sensitive lipase (HSL), which possesses a high affinity for DAG hydrolysis, and ATGL, the major TAG lipase [13] whose is under tight stimulatory control by comparative gene identification 58 (CGI-58) [14] and under inhibitory control by the G0/G1 switch gene 2 [15].

Well before the discovery of ATGL and the proteins directly involved in regulating its activity, a protein decorating the phospholipid membrane of the LDs in white adipose tissue, referred to as perilipin, was discovered in the Londos lab [16]. Based upon its tissue specificity, sensitivity to hormonal and isoproterenol activation and subcellular distribution, this protein was hypothesized to be involved in 'the specialized lipid storage function of adipocytes' [16]. While perilipin (now referred to as PLIN1) is almost exclusively found in adipose tissue, a series of other proteins sharing a high $\mathrm{N}$-terminal sequence homology with perilipin was discovered which are more ubiquitously expressed. Amongst these proteins, referred to as PAT proteins (perilipin, ADRP and TIP47) are adipocyte differentiation related protein (ADRP, now PLIN2) [17], TIP47 (now PLIN3) [18], S3-12 (now PLIN4) [19] and OXPAT [20], LSDP5 [21] and MLDP [22] (now known to be the same protein and referred to as PLIN5). Of these proteins, PLIN2, PLIN3 and PLIN5 are expressed in skeletal muscle. PLIN2 decorates the surface of the LD and dissociates ATGL from the LD thereby inhibiting lipolysis [23]. Similar to PLIN2, PLIN3 localizes to the LD surface, but is also found dispersed throughout the cell and is considered an interchangeable PAT protein that coats nascent LDs and is released from the LD upon LD maturation [24]. Whereas PLIN2 is subject to proteasomal degradation upon release from the LD, PLIN3 has also been reported at the mitochondrial membrane where it is putatively involved in maintaining mitochondrial membrane integrity upon oxidative stress [25] but not upon muscle contraction [26,27].

Probably the most abundant PAT protein in skeletal muscle is PLIN5, which has been reported at the LD surface as well as in vicinity of the mitochondria and LD-mitochondrial contact sites [28]. In conjunction with ATGL and CGI58, PLIN5 regulates LD lipolysis in (oxidative) muscle cells [29] and may be involved in fine tuning lipolytic release of fatty acids for oxidation. Indeed, in the absence of PLIN5, tissues become devoid of LDs [30,31], which appears essential to link IMCL lipolysis to metabolic demand. Even though unilateral overexpression of PLIN5 by electroporation in rats profoundly augments LD storage in a PLIN5 electroporated leg, PLIN5 overexpressing muscle cells are protected against high-fat diet induced insulin resistance [32]. Upon prolonged fasting in humans (a physiological model of insulin resistance) we observed that high levels of PLIN5 in the muscle were protective against the development of muscle insulin resistance [33]. Moreover, we observed using Coherent Anti Raman Spectroscopy (CARS) microscopy that overexpressing PLIN5 profoundly and favorably affected the composition of the lipids sequestered in the LD [34]. Likewise, PLIN5 ablated mice developed muscle insulin resistance (along with accumulation of the putatively insulin desensitizing sphingolipid, ceramide) [30].

Clearly, the proteins mentioned in this section affect the dynamic nature of LDs and may modulate the effects of insulin sensitivity, including morphological changes like altered LD number and size.

\subsection{Morphological characteristics of intramyocellular lipid storage}

While the non-invasive nature of ${ }^{1} \mathrm{H}$ NMR spectroscopy to measure IMCL content actually sparked the majority of papers examining the relationship between IMCL and insulin sensitivity, the pioneering work on this relationship was based on chemical TAG extractions from percutaneous human muscle biopsies [35]. Both methods, however, only give numbers on total muscle TAG content (which is the product of LD number and LD size/volume) but do not permit statements on fiber type specific IMCL storage, LD size, number or subcellular distribution. Conventional light microscopy [11] and fluorescence approaches [36] using lipid soluble dyes circumvent this shortcoming. Such approaches reveal that endurance trained people possess higher IMCL content than type 2 diabetic patients and that the elevated IMCL content is specific 




Fig. 2. Lipid droplets comprise a neutral core that is predominantly triacylglycerol and sterol esters surrounded by a phospholipid monolayer decorated with a variety of proteins. Size, number, subcellular distribution, protein coating, and composition of the lipids in the droplet all have emerged as determinants of the insulin desensitizing effect of excess myocellular lipid droplets. for type I fibers [37]. After 6 months of endurance training of patients with type 2 diabetes, IMCL content increases in both fiber types [38]. Pioneering studies examining IMCL content in a more detailed fashion revealed that LD size [39] and number [37] associate with insulin sensitivity. Accordingly, the number of LDs in insulin sensitive endurance trained athletes is higher compared to T2DM patients [37] and regular training performed by lean sedentary subject augments IMCL content and LD number $[38,40]$, an observation specifically made in type I fibers. Data for LD size are less consistent; large LDs in type I fibers have been reported in some pathophysiological [39] and physiological (prolonged fasting) states of insulin resistance [33], while other studies do not detect significant differences in LD size [37,41]. Insulin sensitivity progressively drops with age; hence, the observation that elderly have larger but fewer LDs than BMI matched young, despite having the same IMCL content [42] also indicates that the presence of large LDs accompanies compromised insulin sensitivity. On the other hand, detailed size analysis using transmission electron microscopy (TEM) reveals that at baseline the excess IMCL in older obese insulin resistant subjects, compared to old lean insulin sensitive subjects, originates from larger LDs [43]; however, after an insulin sensitizing exercise training program, LD size is unaffected. This finding contrasts with a study by He et al. showing that those who decrease LD size most after combined weight loss and exercise training also improve most in insulin sensitivity [39]. It should be noted, though, that the spatial resolution and scattering of out-of-focus light that goes along with conventional wide field light microscopy hampers proper size assessments. While the use of TEM can help to circumvent resolution issues, TEM only permits examination of small fragments of the muscle and does not provide insights on fiber type specific differences. Moreover, 3D reconstruction by TEM is possible, but is far from routine. Highresolution confocal fluorescence microscopy appears to provide the best trade-off between accuracy of size/volume measurements of LD while also permitting co-examination of other proteins or organelles of interest [44].

The putative link between insulin sensitivity and LD size may originate from differences in surface-to-volume, with small droplets having a higher surface-to-volume ratio. Under the assumption of unaltered levels of phospholipids, which make up the LD membrane monolayer, small LDs with high surface-to-volume ratio have a lower lipid interface than larger LDs. The lipid interface of the LD with cytosolic (or LD membrane associated) lipases is essential for lipolytic activity [45]. Thus, a high surface-to-volume ratio may protect against uncontrolled and incomplete lipolysis [46]. While the details of processes governing LD growth and shrinkage are incompletely understood, currently three processes are considered relevant [45]: i) Coalescence of fusion of LDs via pores in the phospholipid monolayer of 2 LDs that results in fusion and exchange of lipids; ii) Ripening of LDs via exchange of molecules from one LD to another, resulting in a linear increase in LD size over time along with an increase in the phospholipids of the LD monolayer and a decrease in size of other LDs, typically resulting in a wider range in LD size; and iii) Expansion of LDs by TAG synthesis fueled by excess fatty acids in the cell. Given that each of these processes distinctly affects the lipid interface, it is not unlikely that the type of process responsible for LD growth also affects the physiological properties of large LDs.

In addition to LD number and size, the subcellular location of LDs also affects insulin sensitivity. LDs can be found dispersed throughout the myofibrillar space (commonly organized alongside the contractile elements) as well as in the near vicinity of the muscle cell membrane (the subsarcolemmal (SS) space). A high number of LDs in the SS region has been associated with insulin resistance $[43,47]$ and in obese insulin resistant subjects, LDs stored in the SS region are larger compared to LDs in lean subjects [43]. Exercise training (generally considered a potent way to improve muscle insulin sensitivity) reduces IMCL content in the SS region by reducing LD size $[41,48]$ and number $[41,48,49]$. Clearly, the spatial distribution of LDs in skeletal muscle, which can be readily observed in longitudinal muscle sections (Fig. 3), is not a random process. Intermyofibrillar LDs are often observed close to mitochondria, which when in the intermyofibrillar space, are commonly observed adjacent to the triads and Z-discs. Thus, even though intermyofibrillar LDs appear distant from the sarcolemma, one should realize that the triads encompass invaginations of the sarcolemma and the sarcoplasmic reticulum (the myocyte equivalent of the endoplasmic reticulum). This location permits interaction of myocellular LDs with structures relevant for insulin signaling, substrate delivery, TAG synthesis and oxidative degradation of fatty acids upon TAG hydrolysis. For a tissue that possesses high fluctuations in energy demand, this location and putative inter-organelle interaction seems rather favorable for maintaining cellular function. Although there is a paucity of experimental data that clearly shows tethering of LDs with mitochondria 


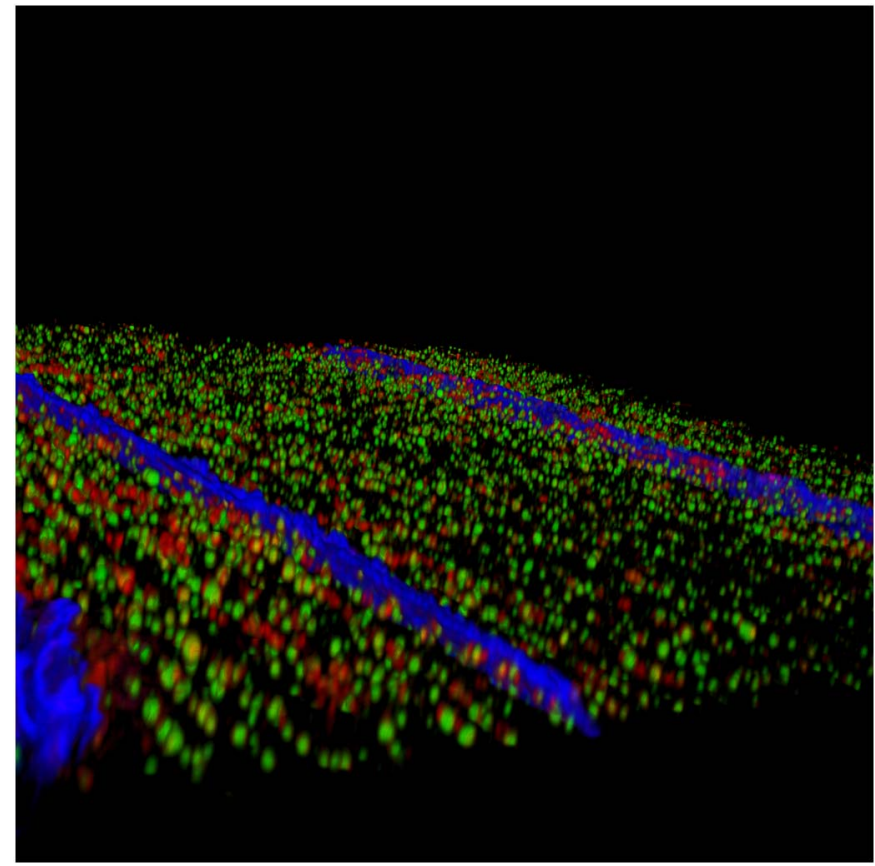

Fig. 3. 3D reconstruction of LDs in a longitudinal section of human skeletal muscle imaged by confocal immunofluorescence microscopy. The sarcolemma (muscle cell membrane) is stained in blue, the lipid droplets are stained in green and the LD coat protein PLIN5 is stained in red. Note that PLIN5 is observed as distinct particles on the droplet and does not entirely cover the LD surface.

and/or the sarcoplasmic reticulum, upon exercise training, the IMCL fraction that is in close contact with mitochondria increases $[40,41,49]$. Given the instability of large LDs and their inefficient lipolysis [50,51], one can hypothesize that increased LD size in the SS region interferes with insulin signaling and promotes insulin resistance.

\subsection{Lipid droplet composition, bioactive lipids and dynamics}

The insulin desensitizing effect of bioactive lipid intermediates like diacylglycerol (DAG) and ceramides in vitro, are more convincing than insulin desensitizing by TAG per se. Diacylglycerol interferes with the insulin signaling by activating PKCs (for review see [52]), which has led to a DAG-centered view in skeletal muscle [53], but ceramides may also block insulin signaling via inhibition of IRS-1, PI3-kinase, and Akt (for review see [54]).

In vivo studies in humans, however, reveal conflicting results for both DAG and ceramides in relation to insulin sensitivity. In diabetesprone offspring of patients with type 2 diabetes, total ceramide content is elevated [55] suggesting ceramides contribute to type 2 diabetes development. In obese patients with type 2 diabetes, both DAG and ceramide levels are increased [56]. Insulin desensitizing interventions like infusion of intralipid into healthy lean subjects increases myocellular levels of DAG in parallel with increased PKCӨ activity and a drop in insulin sensitivity [57], whereas after endurance training, insulin sensitivity improved and saturated DAG and ceramide species decreased in obese individuals and in patients with type 2 diabetes $[56,58]$. Jointly, these observations seem to suggest that DAG and ceramides can impede insulin sensitivity. Conversely, other reports do not observe these differences in groups with diverse levels of insulin sensitivity or upon insulin (de)sensitizing interventions. Cross-sectional observations reveal that obese insulin sensitive individuals have similar total, saturated and unsaturated DAG levels compared to obese insulin resistant individuals, but ceramide levels appear higher in the insulin resistant individuals $[59,60]$. Even though the insulin sensitizing effect of exercise training is consistently reported, some studies also observed improved insulin sensitivity in the absence of changes in DAGs or ceramides [61]. Strikingly, some specific subtypes of DAG levels are even higher in insulin sensitive trained athletes [62]. Gender also seems the affect the putative relation of DAG and ceramides with insulin sensitivity; in female insulin sensitivity drops less after lipid infusion than in males, while changes in DAG and ceramides were similar [63].

Thus, insulin sensitivity (or exercise- or lipid-induced changes herein) cannot be consistently linked to changes in DAG species.

While the pioneering studies on DAG and insulin sensitivity focused on total DAG, evidence is emerging that a better understanding of the relationship between myocellular fat and insulin sensitivity may be achieved by examining DAG subtypes $[62,64,65]$. Subtypes of DAGs not only relate to differences in chain length and saturation, but, importantly, also to the site-specific positions of the fatty-acyl chain on the glycerol backbone. DAG can originate from phospholipids, TAG lipolysis and TAG formation. Depending on its origin, $s n-1,2$ DAG, $s n-2,3$ DAG and $s n-1,3$ DAG can be generated. Only $s n-1,2$ DAG can activate PKCs $[66,67]$, and thus may impede insulin signaling. Interestingly, ATGL can only hydrolyze TAG at the $s n-1$ and $s n-2$ position [68], thereby resulting in $s n-2,3$ DAG or $s n-1,3$ DAG products. Thus, although incomplete hydrolysis of TAG in LDs may increase DAG levels, lipolysis does not give rise $s n-1,2$ DAG, which reportedly originates from phospholipid hydrolysis [69] and hence is released close to the plasma membrane. Although elevated levels of membrane bound sn-1,2 subtype DAG have been observed in subjects with T2DM [57,64], this DAG is unlikely to have originated from myocellular LDs. This notion is supported by examining the stereoisomers of DAG in exercised HSL ablated mice. These mice were highly insulin sensitive despite increased $s n-1,3$ DAG and reduced $s n-1,2$ DAG, indicating that DAG originating from ATGL-mediated lipolysis does not interfere with insulin sensitivity [70]. Therefore, conclusions on the association between DAG and insulin sensitivity based solely upon total DAG levels, must be interpreted with care.

For ceramides the relationship with insulin sensitivity also is not unambiguous. Elevated ceramides levels have been observed in obese insulin resistant subjects $[55,56,59,60,71]$ and in some studies, $[55,56,59,72]$ but not all [71], ceramides have been reported to associate negatively with insulin sensitivity. Moreover, in insulin sensitive endurance trained athletes, ceramide levels are higher than in lean sedentary [73] or glucose intolerant subjects [74]. Lipid infusions induce insulin resistance in the absence of major changes in ceramide content in all studies $[57,63,73,75,76]$, except for one [55]. In addition, ten weeks of endurance training improve insulin sensitivity in lean offspring of patients with type 2 diabetes without changes in ceramide levels [61]. Where changes in ceramides were reported, the reduction in ceramides did not result in improved glucose tolerance [58]. Also for ceramides, subtype specificity and subcellular distribution may determine the association with insulin sensitivity [77]. Of interest is the fact that $\mathrm{C} 16$ to $\mathrm{C} 18$ ceramides in the SS space and de novo synthesis of SS ceramides associated with markers of insulin resistance ceramides [77]. Thus, like DAG ceramide subtypes and subcellular location and/or origin should be taken into account when interpreting the relationship between ceramides and insulin sensitivity.

\section{Human interventions modulating myocellular lipid droplet dynamics and myocellular lipid overflow}

The athlete's paradox [11] suggests that high levels of IMCL may not be harmful in the face of a high oxidative capacity, and it has been hypothesized that having a highly dynamic lipid pool in myocellular LDs may partly explain this dissociation [3,12].

Human clinical investigations have been employed to explore the hypothesis that an overflow of fatty acids to the muscle or hydrolysis of the TAG in myocellular LDs are central to the associations between IMCL and deranged fuel metabolism. LD dynamics have been studied with acute exercise, prolonged fasting and short term high fat diets. A single acute exercise session decreases muscle lipid content in lean 
sedentary subjects $[78,79]$ without affecting muscle PLIN2 and PLIN5 protein content [80], and increases in PLIN3 have been reported after longer bout of endurance exercise [81]. The increase in PLIN3 protein content correlates positively with an increase in ex vivo palmitate oxidation [81]. In vitro studies seem to suggest that this is a cell autonomous effect, as it has been shown that upon treating human primary myotubes with an exercise mimetic cocktail (containing low levels of palmitate, ionomycin and forskolin), PLIN3 protein increases in myotubes from lean sedentary individuals as well as in myotubes from donors with type 2 diabetes [81]. Interestingly, after administration of the same exercise mimetic cocktail to human myotubes cultured from trained endurance athletes, the protein content of PLIN5, instead of PLIN3, increases. These data suggest that LD dynamics in endurance trained athletes may involve proteins other than those involved in LD dynamics in T2DM patients. In that respect, it is of interest to note that induction of PGC1 $\alpha$, either by gene overexpression or by exercise, results in activation of a LD remodeling related gene-set [82]. In addition, exercise-mediated elevation of PLIN5 content in master athletes correlated positively with insulin sensitivity and insulin sensitivity-associated isoforms of specific DAG subtypes [62], suggesting a role for PLIN proteins in modulating both LD dynamics and insulin sensitivity.

LDs in human skeletal muscle are dynamic, and remodeling of LDs can occur within hours. A one-hour submaximal exercise bout reduces number and size of PLIN2- and PLIN5-coated LDs in type I fibers in young, lean, sedentary subjects $[79,80]$ and also reduces the fraction of PLIN2 and PLIN5 in direct contact with the IMCL pool [80]. Models promoting myocellular fatty acid exposure include acute lipid infusion [83,84], prolonged fasting [33] and high fat diets [83,85], all of which profoundly augment IMCL content. In these models increased IMCL content does not always parallel with insulin resistance [33,84,85]. In the face of similar IMCL levels, prior exercise was shown to blunt acute lipid-induced insulin resistance compared to lipid infusions without prior exercise [84]. Similarly, Bachmann et al. [83] showed an increased IMCL content and a concomitant drop in insulin sensitivity upon lipid infusion, as well as after a 3-day HF diet. The inter-individual variation of changes in IMCL content and insulin sensitivity was more pronounced after the HF diet. Interestingly, we recently observed that in Caucasians, the increase in PLIN5 is associated with the maintenance of insulin sensitivity [85], also suggesting a regulatory role for LD coat proteins of the PLIN family in modulating insulin sensitivity. In a model of physiological insulin resistance (prolonged fasting) we quantified LDs decorated with and without PLIN5 (Fig. 3) and observed that the fasting-induced increase in IMCL content was accounted for by increases in number and size of PLIN5-coated LDs [33]. In addition, the increase in PLIN5-coated LDs was associated with maintenance of insulin sensitivity and preservation of mitochondrial oxidative capacity, suggesting a role for PLIN5 in maintaining insulin sensitivity and mitochondrial function when (inactive) muscle is exposed to high levels of fatty acids. These changes in association of PLIN5 with the LD after fasting (but also after acute exercise [79]) occurred without alterations in total PLIN5 protein content in the muscle, suggesting redistribution of PLIN5 between LDs and the cytosol. Jointly, these data suggest that coating the LDs with PLIN proteins affects the dynamic nature of the LD and, via mechanisms currently unknown, modulates muscle insulin sensitivity.

\subsection{Exercise training}

As exercise training-mediated increases in PGC1 $\alpha$ induces genes involved in LD dynamics [82], it was not surprising to note that PLIN5 protein content is elevated in trained individuals compared to lean and/ or obese sedentary subjects $[62,82,86,87]$. Also, other proteins putatively affecting LD dynamics like ATGL [62,87], PLIN2 [82] and PLIN3 [87], are higher in trained than in untrained individuals. On the other hand, an unanticipated negative correlation between ATGL protein content and insulin sensitivity has been reported in patients with type 2 diabetes [88]. Whether these patients also possess lower levels of PLIN proteins is unknown. The negative correlation of ATGL with insulin sensitivity in patients with type 2 diabetes and a low fat oxidative capacity may reflect a lipolytic imbalance between fatty acids released from the LD and the capacity for mitochondrial oxidation of these fatty acids. In the absence of PLIN5 [30] or after inhibiting the interaction of PLIN5 with CGI-58, this co-activator of ATGL may co-localize to ATGL and thereby liberate fatty acids that cannot be shuttled to mitochondrial oxidation. Thus, having high levels of PLIN5 may improve the match between lipolytic rate and subsequent release of fatty acids from the LD with mitochondrial fatty acid oxidation. Indeed, this notion was recently substantiated by studies showing that PLIN5 overexpression in human primary myotubes reduces LD lipolysis and fatty acid oxidation under basal conditions, while upon contraction-mediated elevation of LD lipolysis, PLIN5 overexpression further promotes fatty-acid oxidation [86].

Elevated levels of proteins involved in LD remodeling is not only observed in cross-sectional studies; an increase in PLIN5 is also observed in skeletal muscle after training interventions in both lean sedentary $[79,89]$ and obese subjects $[89,90]$. Some studies have also reported training-induced increases in PLIN2 [38,80,89], PLIN3 [90] and ATGL [91], whereas CGI-58 levels appear unaffected [90,91]. Of note, not only endurance, but also sprint interval training, induces remodeling of PLIN2- and PLIN5-coated LDs [80].

Electron microscopy studies reveal LD-mitochondria interactions after endurance training [40,41,49]. Using immunogold EM we observed that PLIN5 was predominantly present at the LD mitochondria interface [28] and that, upon overexpressing PLIN5 (even in the absence of exercise training) an LD-mitochondrial interaction is promoted $[28,29]$. Moreover, PLIN5 overexpression results in induction of the oxidative phenotype and blunted HF-diet induced insulin resistance [32]. Thus, exercise training induces remodeling of the proteins involved in LD dynamics such that release of fatty acids from the LD better matches mitochondrial fat oxidative capacity. Typically these alterations go along with improved insulin sensitivity.

\subsection{Effects of weight loss on myocellular lipids and insulin resistance}

Calorie restriction and weight loss are interventions that can profoundly affect fuel metabolism, including insulin sensitivity [92]. In parallel with improved insulin sensitivity, weight loss, induced by either diet [93] or bariatric surgery [94], can reduce IMCL, while exercise training generally results in augmented IMCL content. Moreover, weight loss can reduce muscle ceramides [95], although the effects on DAG in muscle are less clear [94]. Thus, insulin sensitivity can be improved by reducing IMCL content via reducing energy intake as well as by increasing energy demand. This apparent discrepancy may originate from differential changes in LD dynamics along with changes in LD proteins. Unfortunately, only one study has reported changes in muscle LD proteins (PLIN2) with weight loss [78]. Additional investigations are clearly warranted to gain a better understanding of how myocellular LD dynamics are altered by weight loss.

\section{Approaches to examine lipid droplets in their native environment}

Commonly used methods to study skeletal muscle LDs include fluorescence and electron microscopy for LD morphology and subcellular distribution, and lipid extractions from muscle homogenates to examine the biochemical composition of the lipids in the LDs. More recently (and hence less commonly used) is the application of imaging mass spectroscopy to obtain information on the composition of the LDs.

\subsection{Examining $L D$ morphology and dynamics}

The high spatial resolution of TEM permits one to distinguish 
between LDs stored in the SS versus the intermyofibrillar (IMF) region and yields ultrastructural information on interorganelle contact sites. The procedures for quantitative TEM, however, are laborious and the essential fixation and dehydration steps raise concerns about the validity of size measurements based upon TEM [44]. Because many of the characteristics of LF and the LD phenotype appear to depend on muscle fiber type, the limited availability to assess muscle fiber type from TEM images is a drawback. Most of these issues of TEM can be circumvented by advanced confocal fluorescence microscopy, which has the spatial resolution for proper measurements of LD size and number while simultaneously giving information on LD coating and subcellular distribution of specific fiber types [33,80]. Moreover, 3D reconstructions of successive z-stacks can be made to provide insight as to how LD coat proteins actually decorate LDs [33]. Thus, it was revealed that PLIN5 does not present as a rim-like structure encapsulating a complete LD $[21,28]$, but as localized (multiple) individual particles at specific sites on the LD [33]. This observation may have important functional implications for the putative docking function PLIN5 may have for lipases or other organelles like mitochondria. With super-resolution microscopy like STimulated Emission Depletion (STED) microscopy, a spatial resolution of $\sim 60 \mathrm{~nm}$ can be reached, which suffices to study the LD protein coating at the nanolevel with simultaneous examination of proteins in the interaction sites between LDs and mitochondria. With this high resolution, STED microscopy will provide more insights into LD dynamics and the proteins that co-localizing with (or are in near vicinity of) the LD.

\subsection{Lipid composition}

To measure the biochemical composition of lipids extracted from skeletal muscle, mass spectrometry is often performed on muscle cell lysates. Although mass spectrometry provides a very detailed analysis of almost all lipid species, it lacks information about organelle-specific lipid composition. This shortcoming can be circumvented by the application of in situ techniques, like Coherent Anti-stokes Raman Scattering (CARS), Time-of-Flight Secondary Ion Mass Spectroscopy (ToF-SIMS), and Matrix-Assisted Laser Desorption Ionization Mass Spectrometry Imaging (MALDI-MSI). These novel technologies provide spatial information on the composition of lipids in defined areas of muscle sections. By using CARS microscopy, chemical bonds of lipidderived molecules can be quantified [96]. Thus, we showed that LDs in sections of PLIN5-overexpressing muscles contain more saturated lipids compared to wild type muscle fibers [34]. For information on different lipid species MALDI-MSI and ToF-SIMS can be applied. ToF-SIMS is a useful tool to measure small molecules at organelle levels, and it can provide information about the fatty acid composition of lipid species $[97,98]$, but it lacks sensitivity in measuring larger molecules. To detect larger molecules like phospholipids, MALDI-MSI can be used, albeit with a lower spatial resolution than ToF-SIMS [99]. Theoretically, ToFSIMS can be applied with a spatial resolution of $\sim 100 \mathrm{~nm}$. In practice, however, a spatial resolution of only $\sim 1000 \mathrm{~nm}$ is reached due to the trade-off of spatial resolution and mass resolving power [100]. For MALDI-MSI spatial resolution of $10 \mu \mathrm{m}$ has been reported [101]. With ToF-SIMS, differences in fatty acid composition of lipid subspecies have been reported to vary in obese and non-obese animals [97]. In skeletal muscle biopsies of young lean, elderly lean and elderly with metabolic syndrome, application of MALDI-MSI revealed different lipid profiles in a fiber type-specific manner [102].

Further refinements, predominantly in spatial resolution, will render these techniques highly valuable in providing data on LD composition in a location-specific manner (i.e. SS vs. IMF) and in LDs that are differentially coated.

\section{Conclusions and future perspectives in human skeletal muscle lipid droplet physiology research}

Even though many studies have been performed during the last two decades to understand the athlete's paradox of high IMCL accompanied by high insulin sensitivity, it is not yet clear which underlying mechanism(s) explains the paradox. Recent developments in imaging techniques will help the field to decipher this paradox. Studies modulating the availability of free fatty acids to the muscle, either pharmacologically or physiologically, already indicate that the coating of the $\mathrm{LD}$ is a determinant of LD functionality and affects the association between intramyocellular lipid storage and insulin sensitivity. Thus far, this type of information remains to be examined in the diseased state. To understand if and how LDs and LD remodeling affect the relationship between intramyocellular lipids and insulin sensitivity will require detailed analyses of the LDs and their associated proteins. In this type of analysis, subcellular distribution, muscle fiber type and interorganelle interactions are anticipated to be important parameters. Thus, future studies should take advantage of the new technologies that permit highresolution analysis of LD-protein-organelle interaction together with in situ analysis of the composition of the lipid moieties in the individual LDs.

\section{Funding}

AG and $\mathrm{MKCH}$ acknowledge financial support from the NanoNextNL, a micro and nanotechnology consortium of the Government of The Netherlands and 130 partners.

\section{Conflict of interest}

The authors have no conflict of interest.

\section{Transparency document}

The http://dx.doi.org/10.1016/j.bbalip.2017.07.010 associated with this article can be found, in online version.

\section{References}

[1] S. Virtue, A. Vidal-Puig, Adipose tissue expandability, lipotoxicity and the metabolic syndrome-an allostatic perspective, Biochim. Biophys. Acta 1801 (2010) 338-349.

[2] T.C. Walther, R.V. Farese Jr., Lipid droplets and cellular lipid metabolism, Annu. Rev. Biochem. 81 (2012) 687-714.

[3] P.M. Badin, D. Langin, C. Moro, Dynamics of skeletal muscle lipid pools, Trends Endocrinol. Metab. 24 (2013) 607-615.

[4] C. Boesch, J. Slotboom, H. Hoppeler, R. Kreis, In vivo determination of intramyocellular lipids in human muscle by means of localized ${ }^{1} \mathrm{H}-\mathrm{MR}$-spectroscopy, Magn. Reson. Med. 37 (1997) 484-493.

[5] S. Jacob, J. Machann, K. Rett, K. Brechtel, A. Volk, W. Renn, E. Maerker, S. Matthaei, F. Schick, C.D. Claussen, H.U. Haring, Association of increased intramyocellular lipid content with insulin resistance in lean nondiabetic offspring of type 2 diabetic subjects, Diabetes 48 (1999) 1113-1119.

[6] M. Krssak, K. Falk Petersen, A. Dresner, L. DiPietro, S.M. Vogel, D.L. Rothman, M. Roden, G.I. Shulman, Intramyocellular lipid concentrations are correlated with insulin sensitivity in humans: a ${ }^{1} \mathrm{H}$ NMR spectroscopy study, Diabetologia 42 (1999) 113-116.

[7] V.B. Schrauwen-Hinderling, M.K. Hesselink, P. Schrauwen, M.E. Kooi, Intramyocellular lipid content in human skeletal muscle, Obesity (Silver Spring, Md.) 14 (2006) 357-367.

[8] G. Boden, B. Lebed, M. Schatz, C. Homko, S. Lemieux, Effects of acute changes of plasma free fatty acids on intramyocellular fat content and insulin resistance in healthy subjects, Diabetes 50 (2001) 1612-1617.

[9] S. Levak-Frank, H. Radner, A. Walsh, R. Stollberger, G. Knipping, G. Hoefler, W. Sattler, P.H. Weinstock, J.L. Breslow, R. Zechner, Muscle-specific overexpression of lipoprotein lipase causes a severe myopathy characterized by proliferation of mitochondria and peroxisomes in transgenic mice, J. Clin. Investig. 96 (1995) 976-986.

[10] J. Hoeks, N.A. van Herpen, M. Mensink, E. Moonen-Kornips, D. van Beurden, M.K. Hesselink, P. Schrauwen, Prolonged fasting identifies skeletal muscle mitochondrial dysfunction as consequence rather than cause of human insulin resistance, Diabetes 59 (2010) 2117-2125. 
[11] B.H. Goodpaster, J. He, S. Watkins, D.E. Kelley, Skeletal muscle lipid content and insulin resistance: evidence for a paradox in endurance-trained athletes, J. Clin. Endocrinol. Metab. 86 (2001) 5755-5761.

[12] D.E. Kelley, L.J. Mandarino, Fuel selection in human skeletal muscle in insulin resistance: a reexamination, Diabetes 49 (2000) 677-683.

[13] R. Zimmermann, J.G. Strauss, G. Haemmerle, G. Schoiswohl, R. BirnerGruenberger, M. Riederer, A. Lass, G. Neuberger, F. Eisenhaber, A. Hermetter, R. Zechner, Fat mobilization in adipose tissue is promoted by adipose triglyceride lipase, Science 306 (2004) 1383-1386.

[14] A. Lass, R. Zimmermann, G. Haemmerle, M. Riederer, G. Schoiswohl, M. Schweiger, P. Kienesberger, J.G. Strauss, G. Gorkiewicz, R. Zechner, Adipose triglyceride lipase-mediated lipolysis of cellular fat stores is activated by CGI-58 and defective in Chanarin-Dorfman syndrome, Cell Metab. 3 (2006) 309-319.

[15] X. Yang, X. Lu, M. Lombes, G.B. Rha, Y.I. Chi, T.M. Guerin, E.J. Smart, J. Liu, The $\mathrm{G}(0) / \mathrm{G}(1)$ switch gene 2 regulates adipose lipolysis through association with adipose triglyceride lipase, Cell Metab. 11 (2010) 194-205.

[16] A.S. Greenberg, J.J. Egan, S.A. Wek, N.B. Garty, E.J. Blanchette-Mackie, C. Londos, Perilipin, a major hormonally regulated adipocyte-specific phosphoprotein associated with the periphery of lipid storage droplets, J. Biol. Chem. 266 (1991) 11341-11346.

[17] D.L. Brasaemle, T. Barber, N.E. Wolins, G. Serrero, E.J. Blanchette-Mackie, C. Londos, Adipose differentiation-related protein is an ubiquitously expressed lipid storage droplet-associated protein, J. Lipid Res. 38 (1997) 2249-2263.

[18] E. Diaz, S.R. Pfeffer, TIP47: a cargo selection device for mannose 6-phosphate receptor trafficking, Cell 93 (1998) 433-443.

[19] N.E. Wolins, J.R. Skinner, M.J. Schoenfish, A. Tzekov, K.G. Bensch, P.E. Bickel, Adipocyte protein S3-12 coats nascent lipid droplets, J. Biol. Chem. 278 (2003) 37713-37721.

[20] N.E. Wolins, B.K. Quaynor, J.R. Skinner, A. Tzekov, M.A. Croce, M.C. Gropler, V. Varma, A. Yao-Borengasser, N. Rasouli, P.A. Kern, B.N. Finck, P.E. Bickel, OXPAT/PAT-1 is a PPAR-induced lipid droplet protein that promotes fatty acid utilization, Diabetes 55 (2006) 3418-3428.

[21] K.T. Dalen, T. Dahl, E. Holter, B. Arntsen, C. Londos, C. Sztalryd, H.I. Nebb, LSDP5 is a PAT protein specifically expressed in fatty acid oxidizing tissues, Biochim. Biophys. Acta 1771 (2007) 210-227.

[22] T. Yamaguchi, S. Matsushita, K. Motojima, F. Hirose, T. Osumi, MLDP, a novel PAT family protein localized to lipid droplets and enriched in the heart, is regulated by peroxisome proliferator-activated receptor alpha, J. Biol. Chem. 281 (2006) $14232-14240$.

[23] L.L. Listenberger, A.G. Ostermeyer-Fay, E.B. Goldberg, W.J. Brown, D.A. Brown, Adipocyte differentiation-related protein reduces the lipid droplet association of adipose triglyceride lipase and slows triacylglycerol turnover, J. Lipid Res. 48 (2007) 2751-2761.

[24] N.E. Wolins, B. Rubin, D.L. Brasaemle, TIP47 associates with lipid droplets, J. Biol. Chem. 276 (2001) 5101-5108.

[25] E. Hocsak, B. Racz, A. Szabo, L. Mester, E. Rapolti, E. Pozsgai, S. Javor, S. Bellyei, F. Gallyas Jr., B. Sumegi, A. Szigeti, TIP47 protects mitochondrial membrane integrity and inhibits oxidative-stress-induced cell death, FEBS Lett. 584 (2010) 2953-2960.

[26] S.V. Ramos, R.E. MacPherson, P.C. Turnbull, K.N. Bott, P. LeBlanc, W.E. Ward, S.J. Peters, Higher PLIN5 but not PLIN3 content in isolated skeletal muscle mitochondria following acute in vivo contraction in rat hindlimb, Phys. Rep. 2 (2014).

[27] S.V. Ramos, P.C. Turnbull, R.E. MacPherson, P.J. LeBlanc, W.E. Ward, S.J. Peters, Changes in mitochondrial perilipin 3 and perilipin 5 protein content in rat skeletal muscle following endurance training and acute stimulated contraction, Exp. Physiol. 100 (2015) 450-462.

[28] M. Bosma, R. Minnaard, L.M. Sparks, G. Schaart, M. Losen, M.H. de Baets, H. Duimel, S. Kersten, P.E. Bickel, P. Schrauwen, M.K. Hesselink, The lipid droplet coat protein perilipin 5 also localizes to muscle mitochondria, Histochem. Cell Biol. 137 (2012) 205-216.

[29] H. Wang, U. Sreenivasan, H. Hu, A. Saladino, B.M. Polster, L.M. Lund, D.W. Gong, W.C. Stanley, C. Sztalryd, Perilipin 5, a lipid droplet-associated protein, provides physical and metabolic linkage to mitochondria, J. Lipid Res. 52 (2011) 2159-2168.

[30] R.R. Mason, R. Mokhtar, M. Matzaris, A. Selathurai, G.M. Kowalski, N. Mokbel, P.J. Meikle, C.R. Bruce, M.J. Watt, PLIN5 deletion remodels intracellular lipid composition and causes insulin resistance in muscle, Mol. Metab. 3 (2014) $652-663$.

[31] K. Kuramoto, T. Okamura, T. Yamaguchi, T.Y. Nakamura, S. Wakabayashi, H. Morinaga, M. Nomura, T. Yanase, K. Otsu, N. Usuda, S. Matsumura, K. Inoue, T. Fushiki, Y. Kojima, T. Hashimoto, F. Sakai, F. Hirose, T. Osumi, Perilipin 5, a lipid droplet-binding protein, protects heart from oxidative burden by sequestering fatty acid from excessive oxidation, J. Biol. Chem. 287 (2012) 23852-23863.

[32] M. Bosma, L.M. Sparks, G.J. Hooiveld, J.A. Jorgensen, S.M. Houten, P. Schrauwen, S. Kersten, M.K. Hesselink, Overexpression of PLIN5 in skeletal muscle promotes oxidative gene expression and intramyocellular lipid content without compromising insulin sensitivity, Biochim. Biophys. Acta 1831 (2013) 844-852.

[33] A. Gemmink, M. Bosma, H.J. Kuijpers, J. Hoeks, G. Schaart, M.A. van Zandvoort, P. Schrauwen, M.K. Hesselink, Decoration of intramyocellular lipid droplets with PLIN5 modulates fasting-induced insulin resistance and lipotoxicity in humans, Diabetologia 59 (2016) 1040-1048.

[34] N. Billecke, M. Bosma, W. Rock, F. Fleissner, G. Best, P. Schrauwen, S. Kersten, M. Bonn, M.K. Hesselink, S.H. Parekh, Perilipin 5 mediated lipid droplet remodelling revealed by coherent Raman imaging, Integr. Biol. 7 (2015) 467-476.
[35] D.A. Pan, S. Lillioja, A.D. Kriketos, M.R. Milner, L.A. Baur, C. Bogardus, A.B. Jenkins, L.H. Storlien, Skeletal muscle triglyceride levels are inversely related to insulin action, Diabetes 46 (1997) 983-988.

[36] R. Koopman, G. Schaart, M.K. Hesselink, Optimisation of oil red O staining permits combination with immunofluorescence and automated quantification of lipids, Histochem. Cell Biol. 116 (2001) 63-68.

[37] L.J. van Loon, R. Koopman, R. Manders, W. van der Weegen, G.P. van Kranenburg, H.A. Keizer, Intramyocellular lipid content in type 2 diabetes patients compared with overweight sedentary men and highly trained endurance athletes, Am. J. Physiol. Endocrinol. Metab. 287 (2004) E558-565.

[38] C.S. Shaw, S.O. Shepherd, A.J. Wagenmakers, D. Hansen, P. Dendale, L.J. van Loon, Prolonged exercise training increases intramuscular lipid content and perilipin 2 expression in type I muscle fibers of patients with type 2 diabetes, Am. J. Physiol. Endocrinol. Metab. 303 (2012) E1158-1165.

[39] J. He, B.H. Goodpaster, D.E. Kelley, Effects of weight loss and physical activity on muscle lipid content and droplet size, Obes. Res. 12 (2004) 761-769.

[40] M.A. Tarnopolsky, C.D. Rennie, H.A. Robertshaw, S.N. Fedak-Tarnopolsky, M.C. Devries, M.J. Hamadeh, Influence of endurance exercise training and sex on intramyocellular lipid and mitochondrial ultrastructure, substrate use, and mitochondrial enzyme activity, Am. J. Physiol. Regul. Integr. Comp. Physiol. 292 (2007) R1271-1278.

[41] I.A. Samjoo, A. Safdar, M.J. Hamadeh, A.W. Glover, N.J. Mocellin, J. Santana, J.P. Little, G.R. Steinberg, S. Raha, M.A. Tarnopolsky, Markers of skeletal muscle mitochondrial function and lipid accumulation are moderately associated with the homeostasis model assessment index of insulin resistance in obese men, PLoS One 8 (2013) e66322.

[42] J.D. Crane, M.C. Devries, A. Safdar, M.J. Hamadeh, M.A. Tarnopolsky, The effect of aging on human skeletal muscle mitochondrial and intramyocellular lipid ultrastructure, J. Gerontol. A Biol. Sci. Med. Sci. 65 (2010) 119-128.

[43] C. Chee, C.E. Shannon, A. Burns, A.L. Selby, D. Wilkinson, K. Smith, P.L. Greenhaff, F.B. Stephens, Relative contribution of Intramyocellular lipid to whole-body fat oxidation is reduced with age but Subsarcolemmal lipid accumulation and insulin resistance are only associated with overweight individuals, Diabetes 65 (2016) 840-850.

[44] S. Daemen, M.A. van Zandvoort, S.H. Parekh, M.K. Hesselink, Microscopy tools for the investigation of intracellular lipid storage and dynamics, Mol. Metab. 5 (2016) 153-163.

[45] A.R. Thiam, R.V. Farese Jr., T.C. Walther, The biophysics and cell biology of lipid droplets, Nat. Rev. Mol. Cell Biol. 14 (2013) 775-786.

[46] M.K. Hesselink, M. Mensink, P. Schrauwen, Intramyocellular lipids and insulin sensitivity: does size really matter? Obes. Res. 12 (2004) 741-742.

[47] J. Nielsen, M. Mogensen, B.F. Vind, K. Sahlin, K. Hojlund, H.D. Schroder, N. Ortenblad, Increased subsarcolemmal lipids in type 2 diabetes: effect of training on localization of lipids, mitochondria, and glycogen in sedentary human skeletal muscle, Am. J. Physiol. Endocrinol. Metab. 298 (2010) E706-713.

[48] Y. Li, S. Lee, T. Langleite, F. Norheim, S. Pourteymour, J. Jensen, H.K. Stadheim, T.H. Storas, S. Davanger, H.L. Gulseth, K.I. Birkeland, C.A. Drevon, T. Holen, Subsarcolemmal lipid droplet responses to a combined endurance and strength exercise intervention, Phys. Rep. 2 (2014).

[49] M.C. Devries, I.A. Samjoo, M.J. Hamadeh, C. McCready, S. Raha, M.J. Watt, G.R. Steinberg, M.A. Tarnopolsky, Endurance training modulates intramyocellular lipid compartmentalization and morphology in skeletal muscle of lean and obese women, J. Clin. Endocrinol. Metab. 98 (2013) 4852-4862.

[50] W. Fei, G. Shui, Y. Zhang, N. Krahmer, C. Ferguson, T.S. Kapterian, R.C. Lin, I.W. Dawes, A.J. Brown, P. Li, X. Huang, R.G. Parton, M.R. Wenk, T.C. Walther, H. Yang, A role for phosphatidic acid in the formation of "supersized" lipid droplets, PLoS Genet. 7 (2011) e1002201.

[51] Y. Guo, T.C. Walther, M. Rao, N. Stuurman, G. Goshima, K. Terayama, J.S. Wong R.D. Vale, P. Walter, R.V. Farese, Functional genomic screen reveals genes involved in lipid-droplet formation and utilization, Nature 453 (2008) 657-661.

[52] S. Timmers, P. Schrauwen, J. de Vogel, Muscular diacylglycerol metabolism and insulin resistance, Physiol. Behav. 94 (2008) 242-251.

[53] V.T. Samuel, K.F. Petersen, G.I. Shulman, Lipid-induced insulin resistance: unravelling the mechanism, Lancet 375 (2010) 2267-2277.

[54] S.A. Summers, Ceramides in insulin resistance and lipotoxicity, Prog. Lipid Res. 45 (2006) 42-72.

[55] M. Straczkowski, I. Kowalska, M. Baranowski, A. Nikolajuk, E. Otziomek, P. Zabielski, A. Adamska, A. Blachnio, J. Gorski, M. Gorska, Increased skeletal muscle ceramide level in men at risk of developing type 2 diabetes, Diabetologia 50 (2007) 2366-2373.

[56] C. Moro, J.E. Galgani, L. Luu, M. Pasarica, A. Mairal, S. Bajpeyi, G. Schmitz, D. Langin, G. Liebisch, S.R. Smith, Influence of gender, obesity, and muscle lipase activity on intramyocellular lipids in sedentary individuals, J. Clin. Endocrinol. Metab. 94 (2009) 3440-3447.

[57] J. Szendroedi, T. Yoshimura, E. Phielix, C. Koliaki, M. Marcucci, D. Zhang, T. Jelenik, J. Muller, C. Herder, P. Nowotny, G.I. Shulman, M. Roden, Role of diacylglycerol activation of PKCtheta in lipid-induced muscle insulin resistance in humans, Proc. Natl. Acad. Sci. U. S. A. 111 (2014) 9597-9602.

[58] C.R. Bruce, A.B. Thrush, V.A. Mertz, V. Bezaire, A. Chabowski, G.J. Heigenhauser, D.J. Dyck, Endurance training in obese humans improves glucose tolerance and mitochondrial fatty acid oxidation and alters muscle lipid content, Am. J. Physiol. Endocrinol. Metab. 291 (2006) E99-E107.

[59] P.M. Coen, J.J. Dube, F. Amati, M. Stefanovic-Racic, R.E. Ferrell, F.G. Toledo, B.H. Goodpaster, Insulin resistance is associated with higher intramyocellular triglycerides in type I but not type II myocytes concomitant with higher ceramide content, Diabetes 59 (2010) 80-88. 
[60] P.M. Coen, K.C. Hames, E.M. Leachman, J.P. Delany, V.B. Ritov, E.V. Menshikova, J.J. Dube, M. Stefanovic-Racic, F.G. Toledo, B.H. Goodpaster, Reduced skeletal muscle oxidative capacity and elevated ceramide but not diacylglycerol content in severe obesity, Obesity (Silver Spring, Md.) 21 (2013) 2362-2371.

[61] D. Sogaard, T. Ostergard, A.U. Blachnio-Zabielska, M. Baranowski, A.H. Vigelso, J.L. Andersen, F. Dela, J.W. Helge, Training does not alter muscle ceramide and diacylglycerol in offsprings of type 2 diabetic patients despite improved insulin sensitivity, J. Diabetes Res. 2016 (2016) 2372741.

[62] F. Amati, J.J. Dube, E. Alvarez-Carnero, M.M. Edreira, P. Chomentowski, P.M. Coen, G.E. Switzer, P.E. Bickel, M. Stefanovic-Racic, F.G. Toledo, B.H. Goodpaster, Skeletal muscle triglycerides, diacylglycerols, and ceramides in insulin resistance: another paradox in endurance-trained athletes? Diabetes 60 (2011) 2588-2597.

[63] B. Vistisen, L.I. Hellgren, T. Vadset, C. Scheede-Bergdahl, J.W. Helge, F. Dela, B. Stallknecht, Effect of gender on lipid-induced insulin resistance in obese subjects, Eur. J. Endocrinol. 158 (2008) 61-68.

[64] B.C. Bergman, D.M. Hunerdosse, A. Kerege, M.C. Playdon, L. Perreault, Localisation and composition of skeletal muscle diacylglycerol predicts insulin resistance in humans, Diabetologia 55 (2012) 1140-1150.

[65] B.C. Bergman, L. Perreault, D.M. Hunerdosse, M.C. Koehler, A.M. Samek, R.H. Eckel, Increased intramuscular lipid synthesis and low saturation relate to insulin sensitivity in endurance-trained athletes, J. Appl. Physiol. 108 (2010) 1134-1141.

[66] L.T. Boni, R.R. Rando, The nature of protein kinase C activation by physically defined phospholipid vesicles and diacylglycerols, J. Biol. Chem. 260 (1985) 10819-10825.

[67] R.R. Rando, N. Young, The stereospecific activation of protein kinase C, Biochem. Biophys. Res. Commun. 122 (1984) 818-823.

[68] T.O. Eichmann, M. Kumari, J.T. Haas, R.V. Farese Jr., R. Zimmermann, A. Lass, R. Zechner, Studies on the substrate and stereo/regioselectivity of adipose triglyceride lipase, hormone-sensitive lipase, and diacylglycerol-O-acyltransferases, J. Biol. Chem. 287 (2012) 41446-41457.

[69] T.O. Eichmann, A. Lass, DAG tales: the multiple faces of diacylglycerol-stereochemistry, metabolism, and signaling, Cell. Mol. Life Sci. 72 (2015) 3931-3952.

[70] A.K. Serup, T.J. Alsted, A.B. Jordy, P. Schjerling, C. Holm, B. Kiens, Partial disruption of lipolysis increases postexercise insulin sensitivity in skeletal muscle despite accumulation of DAG, Diabetes 65 (2016) 2932-2942.

[71] J.M. Adams II, T. Pratipanawatr, R. Berria, E. Wang, R.A. DeFronzo, M.C. Sullards, L.J. Mandarino, Ceramide content is increased in skeletal muscle from obese insulin-resistant humans, Diabetes 53 (2004) 25-31.

[72] M. Straczkowski, I. Kowalska, A. Nikolajuk, S. Dzienis-Straczkowska, I. Kinalska, M. Baranowski, M. Zendzian-Piotrowska, Z. Brzezinska, J. Gorski, Relationship between insulin sensitivity and sphingomyelin signaling pathway in human skeletal muscle, Diabetes 53 (2004) 1215-1221.

[73] L.S. Chow, D.G. Mashek, E. Austin, L.E. Eberly, X.M. Persson, M.T. Mashek, E.R. Seaquist, M.D. Jensen, Training status diverges muscle diacylglycerol accumulation during free fatty acid elevation, Am. J. Physiol. Endocrinol. Metab. 307 (2014) E124-131.

[74] M. Skovbro, M. Baranowski, C. Skov-Jensen, A. Flint, F. Dela, J. Gorski, J.W. Helge, Human skeletal muscle ceramide content is not a major factor in muscle insulin sensitivity, Diabetologia 51 (2008) 1253-1260.

[75] J. Hoeks, M. Mensink, M.K. Hesselink, K. Ekroos, P. Schrauwen, Long- and medium-chain fatty acids induce insulin resistance to a similar extent in humans despite marked differences in muscle fat accumulation, J. Clin. Endocrinol. Metab. 97 (2012) 208-216.

[76] B. Nowotny, L. Zahiragic, D. Krog, P.J. Nowotny, C. Herder, M. Carstensen, T. Yoshimura, J. Szendroedi, E. Phielix, P. Schadewaldt, N.C. Schloot, G.I. Shulman, M. Roden, Mechanisms underlying the onset of oral lipid-induced skeletal muscle insulin resistance in humans, Diabetes 62 (2013) 2240-2248.

[77] J.O. Chung, C. Koutsari, A.U. Blachnio-Zabielska, K.C. Hames, M.D. Jensen, Intramyocellular ceramides - sub-cellular concentrations and fractional de novo synthesis in postabsorptive humans, Diabetes (2017).

[78] S.A. Phillips, C.C. Choe, T.P. Ciaraldi, A.S. Greenberg, A.P. Kong, S.C. Baxi, L. Christiansen, S.R. Mudaliar, R.R. Henry, Adipocyte differentiation-related protein in human skeletal muscle: relationship to insulin sensitivity, Obes. Res. 13 (2005) 1321-1329.

[79] S.O. Shepherd, M. Cocks, K.D. Tipton, A.M. Ranasinghe, T.A. Barker, J.G. Burniston, A.J. Wagenmakers, C.S. Shaw, Preferential utilization of perilipin 2-associated intramuscular triglycerides during $1 \mathrm{~h}$ of moderate-intensity endurance-type exercise, Exp. Physiol. 97 (2012) 970-980.

[80] S.O. Shepherd, M. Cocks, K.D. Tipton, A.M. Ranasinghe, T.A. Barker, J.G. Burniston, A.J. Wagenmakers, C.S. Shaw, Sprint interval and traditional en durance training increase net intramuscular triglyceride breakdown and expression of perilipin 2 and 5, J. Physiol. 591 (2013) 657-675.

[81] J.D. Covington, J.E. Galgani, C. Moro, J.M. LaGrange, Z. Zhang, A.C. Rustan, E. Ravussin, S. Bajpeyi, Skeletal muscle perilipin 3 and coatomer proteins are increased following exercise and are associated with fat oxidation, PLoS One 9
(2014) e91675.

[82] T.R. Koves, L.M. Sparks, J.P. Kovalik, M. Mosedale, R. Arumugam, K.L. DeBalsi, K. Everingham, L. Thorne, E. Phielix, R.C. Meex, C.L. Kien, M.K. Hesselink, P. Schrauwen, D.M. Muoio, PPARgamma coactivator-1alpha contributes to exercise-induced regulation of intramuscular lipid droplet programming in mice and humans, J. Lipid Res. 54 (2013) 522-534.

[83] O.P. Bachmann, D.B. Dahl, K. Brechtel, J. Machann, M. Haap, T. Maier, M. Loviscach, M. Stumvoll, C.D. Claussen, F. Schick, H.U. Haring, S. Jacob, Effects of intravenous and dietary lipid challenge on intramyocellular lipid content and the relation with insulin sensitivity in humans, Diabetes 50 (2001) 2579-2584.

[84] S.A. Newsom, S. Schenk, M. Li, A.C. Everett, J.F. Horowitz, High fatty acid availability after exercise alters the regulation of muscle lipid metabolism, Metab. Clin. Exp. 60 (2011) 852-859.

[85] A. Gemmink, L.E. Bakker, B. Guigas, E. Kornips, G. Schaart, A.E. Meinders, I.M. Jazet, M.K. Hesselink, Lipid droplet dynamics and insulin sensitivity upon a 5day high-fat diet in Caucasians and South Asians, Sci Rep 7 (2017) 42393.

[86] C. Laurens, V. Bourlier, A. Mairal, K. Louche, P.M. Badin, E. Mouisel, A. Montagner, A. Marette, A. Tremblay, J.S. Weisnagel, H. Guillou, D. Langin, D.R. Joanisse, C. Moro, Perilipin 5 fine-tunes lipid oxidation to metabolic demand and protects against lipotoxicity in skeletal muscle, Sci Rep 6 (2016) 38310.

[87] A. Vigelso, C. Prats, T. Ploug, F. Dela, J.W. Helge, Higher muscle content of perilipin 5 and endothelial lipase protein in trained than untrained middle-aged men, Physiol. Res./Acad. Sci. Bohemoslov. (2015).

[88] P.M. Badin, K. Louche, A. Mairal, G. Liebisch, G. Schmitz, A.C. Rustan, S.R. Smith, D. Langin, C. Moro, Altered skeletal muscle lipase expression and activity contribute to insulin resistance in humans, Diabetes 60 (2011) 1734-1742.

[89] S.J. Peters, I.A. Samjoo, M.C. Devries, I. Stevic, H.A. Robertshaw, M.A. Tarnopolsky, Perilipin family (PLIN) proteins in human skeletal muscle: the effect of sex, obesity, and endurance training, Appl. Physiol. Nutr. Metab. (Physiol. Appl. Nutr. Metab) 37 (2012) 724-735.

[90] K. Louche, P.M. Badin, E. Montastier, C. Laurens, V. Bourlier, I. de Glisezinski, C. Thalamas, N. Viguerie, D. Langin, C. Moro, Endurance exercise training upregulates lipolytic proteins and reduces triglyceride content in skeletal muscle of obese subjects, J. Clin. Endocrinol. Metab. 98 (2013) 4863-4871.

[91] T.J. Alsted, L. Nybo, M. Schweiger, C. Fledelius, P. Jacobsen, R. Zimmermann, R. Zechner, B. Kiens, Adipose triglyceride lipase in human skeletal muscle is upregulated by exercise training, Am. J. Physiol. Endocrinol. Metab. 296 (2009) E445-453.

[92] D.E. Kelley, B. Goodpaster, R.R. Wing, J.A. Simoneau, Skeletal muscle fatty acid metabolism in association with insulin resistance, obesity, and weight loss, Am. J. Phys. 277 (1999) E1130-1141.

[93] B.H. Goodpaster, R. Theriault, S.C. Watkins, D.E. Kelley, Intramuscular lipid content is increased in obesity and decreased by weight loss, Metab. Clin. Exp. 49 (2000) 467-472.

[94] P.M. Coen, E.V. Menshikova, G. Distefano, D. Zheng, C.J. Tanner, R.A. Standley, N.L. Helbling, G.S. Dubis, V.B. Ritov, H. Xie, M.E. Desimone, S.R. Smith, M. Stefanovic-Racic, F.G. Toledo, J.A. Houmard, B.H. Goodpaster, Exercise and weight loss improve muscle mitochondrial respiration, lipid partitioning, and insulin sensitivity after gastric bypass surgery, Diabetes 64 (2015) 3737-3750.

[95] J.J. Dube, F. Amati, F.G. Toledo, M. Stefanovic-Racic, A. Rossi, P. Coen, B.H. Goodpaster, Effects of weight loss and exercise on insulin resistance, and intramyocellular triacylglycerol, diacylglycerol and ceramide, Diabetologia 54 (2011) 1147-1156.

[96] N. Billecke, G. Rago, M. Bosma, G. Eijkel, A. Gemmink, P. Leproux, G. Huss, P. Schrauwen, M.K. Hesselink, M. Bonn, S.H. Parekh, Chemical imaging of lipid droplets in muscle tissues using hyperspectral coherent Raman microscopy, Histochem. Cell Biol. 141 (2014) 263-273.

[97] Y.K. Magnusson, P. Friberg, P. Sjovall, J. Malm, Y. Chen, TOF-SIMS analysis of lipid accumulation in the skeletal muscle of ob/ob mice, Obesity (Silver Spring, Md.) 16 (2008) 2745-2753.

[98] P. Sjovall, M. Rossmeisl, J. Hanrieder, O. Kuda, J. Kopecky, M. Bryhn, Dietary uptake of omega-3 fatty acids in mouse tissue studied by time-of-flight secondary ion mass spectrometry (TOF-SIMS), Anal. Bioanal. Chem. 407 (2015) 5101-5111.

[99] N. Goto-Inoue, Y. Manabe, S. Miyatake, S. Ogino, A. Morishita, T. Hayasaka, N. Masaki, M. Setou, N.L. Fujii, Visualization of dynamic change in contractioninduced lipid composition in mouse skeletal muscle by matrix-assisted laser desorption/ionization imaging mass spectrometry, Anal. Bioanal. Chem. 403 (2012) 1863-1871.

[100] S.G. Boxer, M.L. Kraft, P.K. Weber, Advances in imaging secondary ion mass spectrometry for biological samples, Annu. Rev. Biophys. 38 (2009) 53-74.

[101] L.A. McDonnell, R.M. Heeren, Imaging mass spectrometry, Mass Spectrom. Rev. 26 (2007) 606-643.

[102] M. Gueugneau, C. Coudy-Gandilhon, L. Theron, B. Meunier, C. Barboiron, L. Combaret, D. Taillandier, C. Polge, D. Attaix, B. Picard, J. Verney, F. Roche, L. Feasson, J.C. Barthelemy, D. Bechet, Skeletal muscle lipid content and oxidative activity in relation to muscle fiber type in aging and metabolic syndrome, J. Gerontol. Ser. A Biol. Sci. Med. Sci. 70 (2015) 566-576. 